\title{
Emerging Measurement Techniques for Airborne Pollutants
}

\author{
Ki-Hyun Kim ${ }^{1}$ and Richard J. C. Brown ${ }^{2}$ \\ ${ }^{1}$ Atmospheric Environment Laboratory, Department of Environment and \\ Energy, Sejong University, 98 Goon Ja Dong, Gwang Jin Goo, Seoul 143-747, \\ Republic of Korea \\ ${ }^{2}$ Analytical Science Division, National Physical Laboratory, Teddington TW11 OLW, UK
}

Received 23 November 2011; Accepted 23 November 2011

The quality of the air we breathe in many parts of the world has been improved dramatically by a series of clean air regulations dating back over fifty years, including the "clean air acts" passed by the UK government (1956) [1], the federal governments of USA (1963), and those passed by many other countries. As a result, the health of the human population and our surrounding aquatic and terrestrial biosystems has benefited. However, several factors underpin the continued and increasing global effort to measure pollutants in ambient air:

(i) burgeoning and more exacting national and international legislation governing the allowable concentration of pollutants in ambient air and in emissions,

(ii) a greater understanding of the detrimental effects of a variety of pollutants on human health and environmental sustainability,

(iii) significant improvements in technology allowing an increasing range and complexity of pollutants to be measured at ever lower concentrations, including real-time and automatic analyses,

(iv) recognition that many pollutants undergo long-range transport and must be considered as a global issue requiring integrated and transboundary solutions, for example, mercury vapour,

(v) the need to perform source apportionment studies to correctly target emissions abatement and control strategies,

(vi) a requirement for more cost-effective measurement solutions to address pollution issues in the developing world and to respond to increasing cost pressures in the developed world.

As such, it is not surprising that the number of pollutants covered by national and international legislation have increased in both number and complexity in recent years. The measurement infrastructure required to cope with these demands has also had to increase. Indeed, Figure 1 shows the evolution over time of the number of government-funded automatic measurement stations in the UK, clearly displaying the effect of the introduction of a series of European air quality assessment management Directives from 1996 onwards [2].

In addition to air-quality monitoring becoming more extensive, the complexity and quantity of the data produced by these measurements has similarly expanded, requiring new methods to analyse and extract relevant information from large data sets. Furthermore, the global nature of many pollutants, plus the 


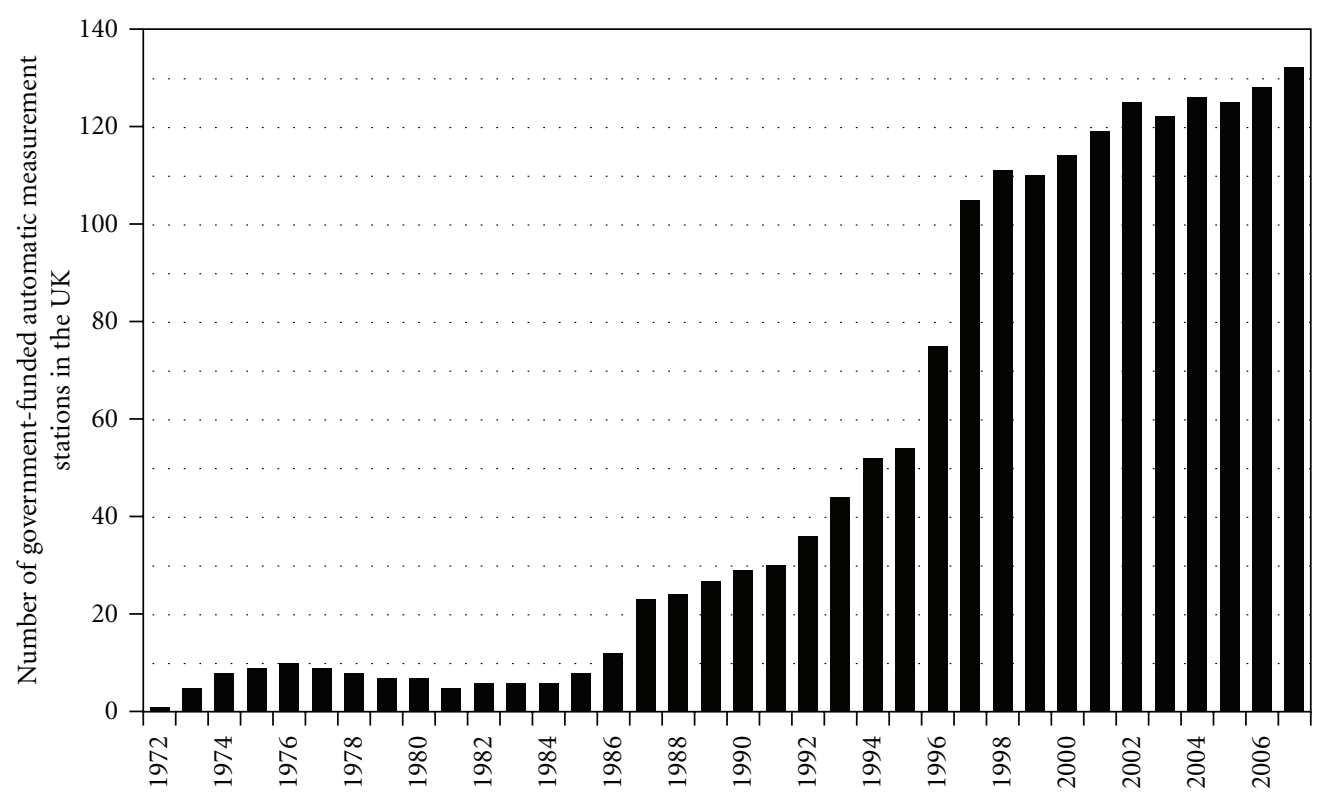

FIGURE 1: Evolution from 1972 to 2007 of the number of government-funded automatic measurement stations in the UK, reproduced from [3].

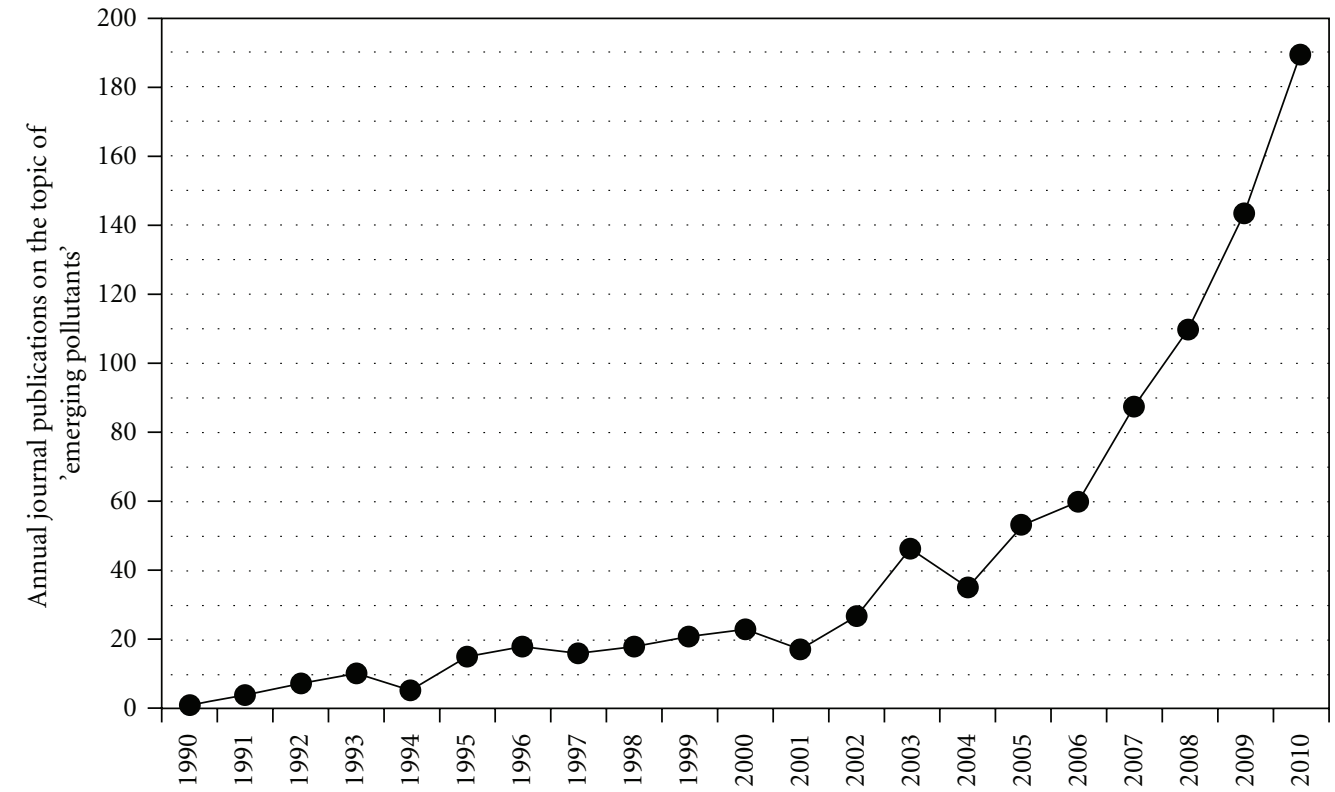

FIGURE 2: The annual number of peer-reviewed journal articles published under the topic of "emerging pollutants" from 1990 to 2010, adapted from [4].

requirement to comply with legislative limit values, has reinforced the requirements for all air-quality data to be traceable to the SI system of units with uncertainties that are fit for purpose to ensure comparability between different locations and over time, regardless of the measurement method used.

The upsurge in activity in the "emerging pollutants" area generated by all of these related drivers is clear from the increase in the number of publications on the topic each year over the last twenty years, as 
shown in Figure 2. Therefore, this special issue aims to bring together some of the recent and most exciting developments in the area, addressing some of the themes discussed above and describing current activity in the field. It contains a mixture of papers describing: the latest instrumentation developed for measurements of air pollutants relevant to health and climate change in the form of nephelometry, measurement techniques for emerging airborne pollutants of global concern at ultralow levels and in complex environmentsrepresented here by mercury and volatile organic compounds, and an example of an integrated national monitoring network with long-term data sets for multiple key atmospheric species and emerging pollutants such as ammonia and acid deposition.

Continuation of collaborative efforts to further develop and improve these techniques for measuring airborne pollutants will not only help us access new datasets but also will lead ultimately to improvements to the quality of life of the global population through development of more refined abatement technologies and the tightening of environmental regulations.

\section{ACKNOWLEDGMENT}

The first author would like to acknowledge the partial support made by a National Research Foundation of Korea (NRF) grant funded by the Ministry of Education, Science and Technology (MEST) (no. 20090093848).

\section{REFERENCES}

[1] Clean Air Act 1956, October 2011, http://www.legislation.gov.uk/ukpga/Eliz2/4-5/52/contents/enacted.

[2] European Ambient Air Quality Legislation, October 2011, http://ec.europa.eu/environment/air/legis.htm.

[3] A brief history of monitoring networks, October 2011, http://uk-air.defra.gov.uk/networks/brief-history.

[4] Thomson Reuters Web of Science, October 2011, http://www.webofknowledge.com/.

\section{This article should be cited as follows:}

Ki-Hyun Kim and Richard J. C. Brown, "Emerging Measurement Techniques for Airborne Pollutants," TheScientificWorldJOURNAL, vol. 11, pp. 2599-2601, 2011. 

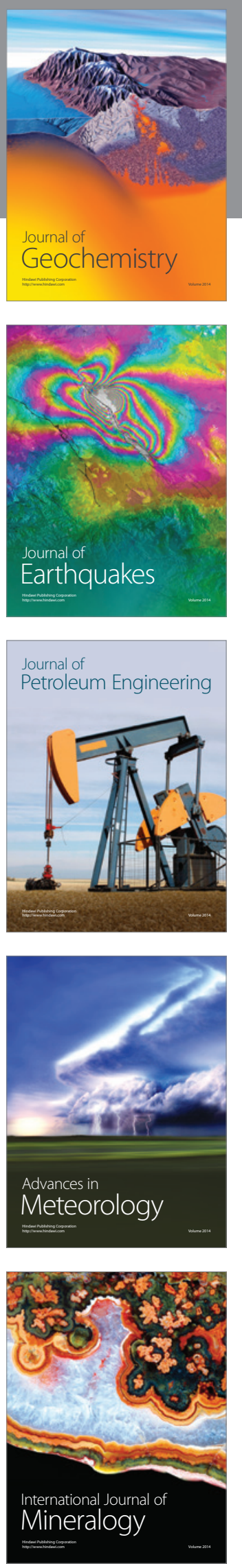
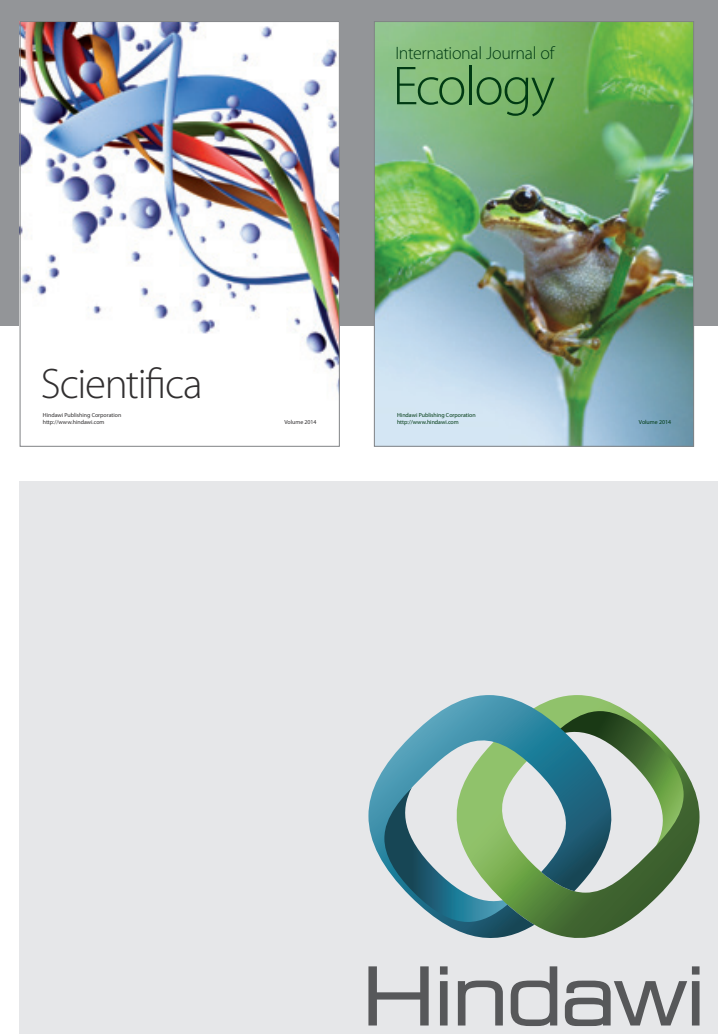

Submit your manuscripts at http://www.hindawi.com
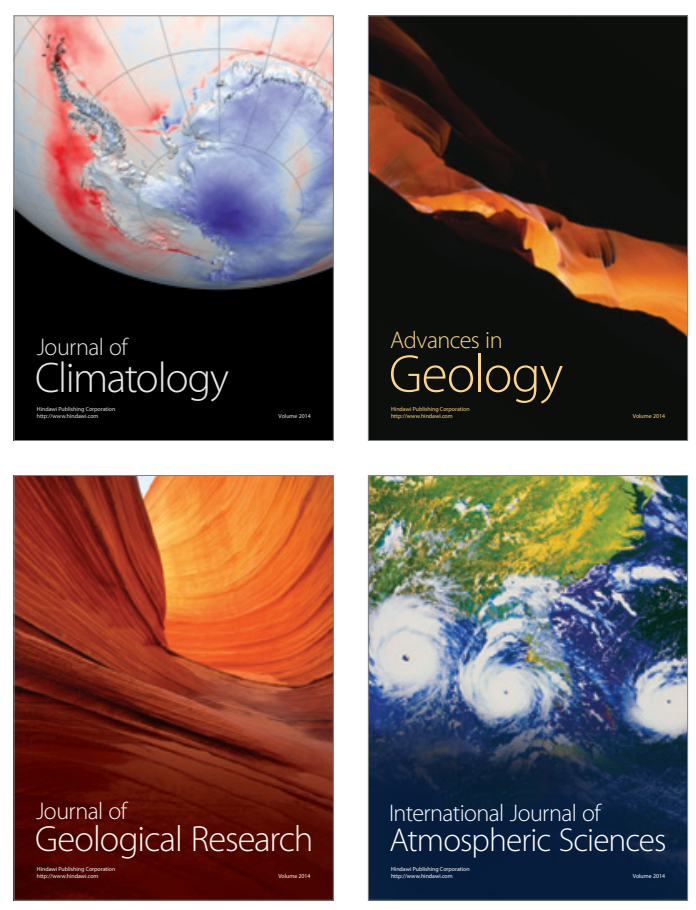
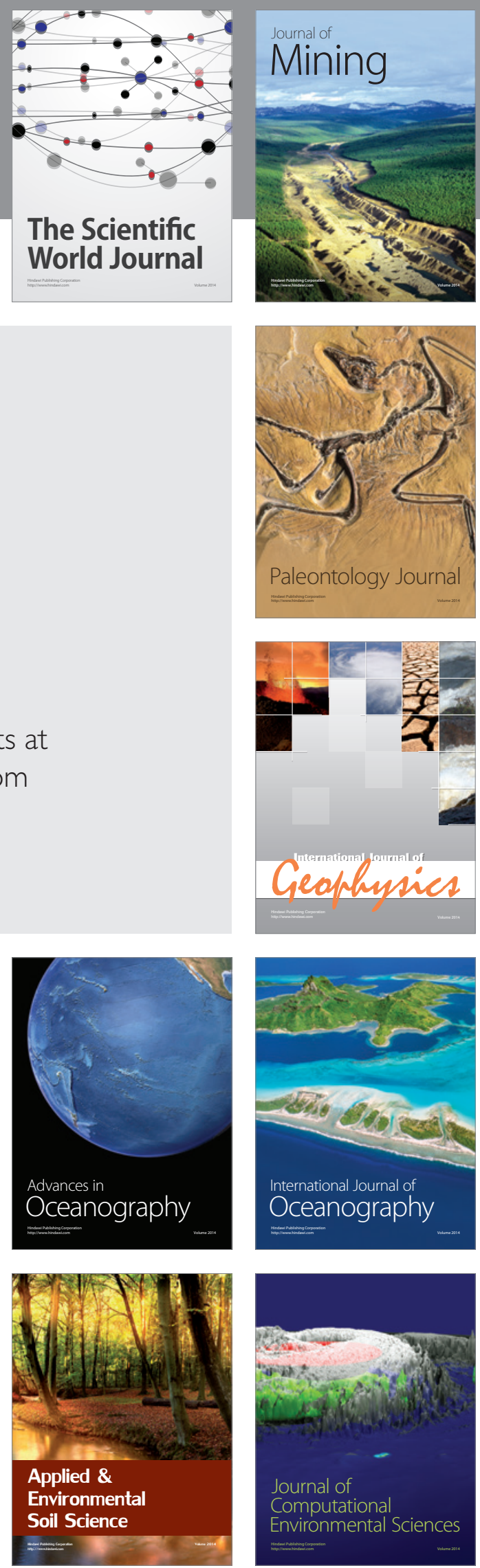